\title{
Research Paper: The Effect of Parental Medical History on the Prevalence of Cerebrovascular Diseases in Their Children in an Iranian Population
}

\author{
Alireza Khosravi' ${ }^{1}$ (D, Mohaddeseh Behjati2 ${ }^{\star \star}$ (D, Minoo Dianatkhah ${ }^{3}$, Fatemeh Noori ${ }^{3}$, Majid Nejati ${ }^{4}$, Nizal Sarrafzadegan \\ 1. Hypertension Research Center, Cardiovascular Research Institute, Isfahan University of Medical Sciences, Isfahan, Iran \\ 2. Rajaie Cardiovascular Medical and Research Center, Iran University of Medical Science, Tehran, Iran. \\ 3. Heart Failure Research Center, Cardiovascular Research Institute, Isfahan University of Medical Science, Isfahan, Iran. \\ 4. Anatomical Sciences Research Center, Kashan University of Medical Sciences, Kashan, Iran.
}

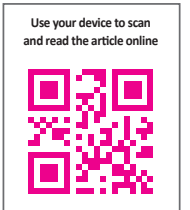

Chtat On: Khosravi, A., Behjati, M., Dianatkhah, M., Noori, F., Nejati, M., \& Sarrafzadegan, N. (2018). The Effect of Parental Medical History on the Prevalence of Cerebrovascular Diseases in Their Children in an Iranian Population. Basic and Clinical Neuroscience, 9(5), 367-372. http://dx.doi.org/10.32598/bcn.9.5.367

http://dx.doi.org/10.32598/bcn.9.5.367

Keywords:

Parental, Medical history, Cerebrovascular, Children

\begin{abstract}
A B S T RA C T
Introduction: still a controversial issue, family history is known as a risk factor for the development of Cerebrovascular Diseases (CVD). In this study, we aimed to evaluate the relationship between parental history and risk of CVD in their offspring in Iranian population.

Methods: Isfahan Cohort Study (ICS) included total 6504 healthy participants which were randomly selected through a two-stage cluster sampling method from three districts. The participants were followed prospectively for 10 years. The diagnosis of CVD were confirmed by expert panelist. Clinically validated history of CVD was established for definition of parental history of CVD. Types of history were categorized into paternal, maternal, both parents, and no history.

Results: The prevalence of CVD is generally higher among female offspring compared with male ones $(\mathrm{P}<0.001)$. The relative risk of CVD with maternal history was not significant $(95 \% \mathrm{CI}=0.95-2.29)$. By adjusted model analysis, history of CVD in both parents affected the risk of $\mathrm{CVD}$ in their male children $(\mathrm{RR}=2.13, \mathrm{P}=0.033,95 \% \mathrm{CI})$. By crude model analysis, maternal history of CVD $(\mathrm{P}=0.047)$, history of $\mathrm{CVD}$ in both parents $(\mathrm{P}=0.032)$, and maternal history of hypertension $(\mathrm{P}=0.005)$ were determined as risk factors of $\mathrm{CVD}$ in offspring. Indeed, the mean age of CVD in offspring decreases based on this order: history of hypertension in parents, paternal history of CVD in both parents, maternal history of CVD, and no history $(\mathrm{P}<0.001)$

Conclusion: Early and regular screening for CVD development is necessary in female offspring of the families with the present history of CVD from maternal side. This group are at risk and should be considered as the target group for screening and taking preventive measures.
\end{abstract}




\section{Highlights}

- Maternal transmission of cerebrovascular diseases imposes a greater risk on their offspring.

- Women with a maternal history of cerebrovascular disease are more susceptible to develop cerebrovascular diseases.

- Age of cerebrovascular disease onset in patients with positive family history is lower than the normal population.

\section{Plain Language Summary}

The role of genetics in Cerebrovascular Diseases (CVDs) is not obvious. Traditional risk factors such as hypertension, diabetes mellitus, hyperlipidemia, obesity and smoking association with parental history of CVD were investigated. Maternal history of CVD, history of CVD in both parents and maternal history of hypertension were determined as risk factors of CVD in offspring. This study results indicate that the prevalence of CVD in female offspring of people with a positive CVD history is more than male offspring. The onset age of CVD in offspring decreases based on this order as history of hypertension in parents, paternal history of CVD in both parents, maternal history of CVD, and no history. It seems essential that earlier and regular screening of CVD be done in female offspring with maternal history of CVD.

\section{Introduction}

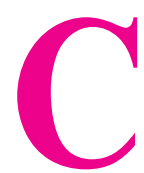

erebrovascular Diseases (CVDs) are multifactorial diseases, caused by environmental factors and poor lifestyle choices such as poor diet, smoking and other predisposing diseases. Although the role of genetics in CVD has been already discussed, the effect of parental history of CVD on offspring CVD risk is unclear (Seshadri et al., 2010). Numerous studies explored the relationship between family history and risk for stroke (Chung et al., 2016; Tian et al., 2017).

Such family history has been reported by various studies on twin and animal models (Jood, Ladenvall, Rosengren, Blomstrand, \& Jern, 2005; Aparicio \& Seshadri, 2017). CVD has a substantial familial aggregation and heritability in certain families that result in its earlier development (Bak, Gaist, Sindrup, Skytthe, \& Christensen, 2002; Seshadri et al., 2006). The risk of stroke in middleaged to old-aged people is partly associated with a family history of stroke. This familial history provokes the risk for both hemorrhagic and ischemic stroke and post hospital discharge neurobehavioral outcomes, especially in young women (Kim et al., 2004).

Parental history of Coronary Heart Disease (CHD) is an obvious risk factor for the occurrence of disease in the offspring. However, clear correlation has not been established between CVD and family history yet (Sholtz, Rosenmanr, \& Brandr, 1975; Jousilahti, Puska, Vartiainen, Pekkanen, \& Tuomilehto, 1996). It has been demonstrated that positive family history of stroke is associ- ated with increased risk of stroke in females compared with males with more association from maternal side (Tentschert, Greisenegger, Wimmer, Lang, \& Lalouschek, 2003; Seshadri et al., 2010). The cause of such correlation is unknown; however, genetic factors seem to have the main role (Huang et al., 1994).

According to Floßmann, Schulz and Rothwell (2004) the impact of family history on CVD in offspring is very heterogeneous. This heterogeneity could be attributed to different study populations, insufficient details, or research bias (Øygarden et al., 2015). Thus, it seems necessary to entirely determine the inheritance pattern of this disease for each population, to provide better preventive, diagnostic, and therapeutic options for at-risk subgroups. Understanding the detailed family history of CVD with special attention to sex differences can help develop preventive programs or risk assessment prediction models. Therefore, this study aimed to evaluate and compare the impact of maternal and paternal history of CVD on the risk of CVD development in the offspring of study population.

\section{Methods}

Isfahan Cohort Study (ICS) is a 10-year longitudinal prospective and ongoing population-based study, which began in 2001 (January 2 to September 28 ) (Sarrafzadegan et al., 2011). ICS followed up 6504 individuals, aged 35 years or more. In total, $51 \%$ of the participants were women. The samples were selected from rural and urban areas in 3 districts, including Najafabad, Arak and Isfahan cities, Iran. Of them, 6323 were initially free from CVD. According to WHO definition, stroke is a rapid- 
onset focal neurological disorder with probable vascular cause lasting more than 24 hours. A combination of stroke and IHD was used to define CVD.

The final diagnosis was made by a panel of neurologists and cardiologists based on medical records, while verbal autopsy was conducted for deaths in the followup (Sarrafzadegan, Sadeghi, Oveisgharan, \& Iranipour, 2013). Self-reported history of CVD was used to define parental history of CVD. Types of parental history of CVD were categorized as: no parental history of CVD, both parental history of CVD or Hypertension (HTN).

For statistical analysis, the relative risk and 95\% Confidence Interval (CI) of HTN, Diabetes Mellitus (DM), hyperlipidemia, obesity and smoking and association of these risk factors with parental history of CVD were investigated. All participants who had CVD during followup were selected as the case group and those who did not were selected as the control group. Both groups were matched in time of follow-up (density sampling), so that the effect of time on the risk was similar.

Statistical analyses were performed using SPSS. Multivariable analysis was performed to determine effect of parental history of hypertension on occurrence of hypertension in their offspring. Both crude and adjusted model were applied for analysis of data. Adjustment was performed based on age, gender and Body Mass Index (BMI) of offspring.

\section{Results}

The study results indicated that the overall prevalence of CVD in female offspring of people with a positive CVD history is more than male offspring $(\mathrm{P}<0.001)$. Table 1 demonstrates the gender-specific distribution of CVD with respect to the parental history. Table 1 also presents risk factors and demographic data regarding CVD in the offspring. According to crude analysis, DM (3.07, CI: 2.49-3.79), age older than 60 years (3.04, $\mathrm{CI}=2.54-3.63), \mathrm{BMI}>30(1.25, \mathrm{CI}=1.02-1.53)$, and female gender (0.78, CI: 0.66-0.93) were significantly related with CVD in offspring. Adjusted model revealed that, age older than 60 years $(3.22, \mathrm{CI}=2.68-3.85), \mathrm{DM}$ (1.76, $\mathrm{CI}=1.76-2.80), \mathrm{BMI}>30 \quad(1.49, \mathrm{CI}=1.21-1.84)$, maternal history of HTN (1.45, CI=1.11-1.89), female gender $(0.70, \mathrm{CI}=0.58-0.84)$, and history of CVD alone in both parents influenced the risk for CVD in male offspring $(\mathrm{RR}=2.13, \mathrm{P}=0.033,95 \% \mathrm{CI})$.

Although the relative risk of maternal history of CVD was higher than paternal history, the difference was not significant $(\mathrm{CI}=0.95-2.29)$. Presence or absence of parental history of HTN (each type) does not influence the development of CVD in offspring. By crude model

Table 1. The relationship between CVD risk factors and family history of participants based on parental history

\begin{tabular}{|c|c|c|c|c|c|c|c|}
\hline $\begin{array}{l}\text { Offspring } \\
\text { Variable }\end{array}$ & $\begin{array}{l}\text { No History } \\
(n=434)\end{array}$ & $\begin{array}{l}\text { Father or Mother } \\
\qquad(n=506)\end{array}$ & $\mathbf{P}$ & $\begin{array}{l}\text { Father } \\
(n=297)\end{array}$ & $\begin{array}{l}\text { Mother } \\
(n=209)\end{array}$ & $\begin{array}{l}\text { Both } \\
(n=51)\end{array}$ & $\mathbf{P}$ \\
\hline Sex (Male) & $196(45.2)$ & $243(43.6)$ & $<0.001$ & $156(52.5)$ & $71(34.0)$ & $16(31.4)$ & $<0.001$ \\
\hline Age at baseline & $49.3 \pm 10.9$ & $47.6 \pm 9.5$ & 0.010 & $47.0 \pm 9.51$ & $48.4 \pm 9.74$ & $47.8 \pm 8.95$ & 0.281 \\
\hline BMI & $26.9 \pm 4.52$ & $27.6 \pm 4.46$ & 0.020 & $27.4 \pm 4.28$ & $27.8 \pm 4.70$ & $28.1 \pm 4.48$ & 0.386 \\
\hline Smoking & $90(20.7)$ & $117(21.1)$ & 0.895 & $71(24.1)$ & $38(18.2)$ & $8(15.7)$ & 0.171 \\
\hline Diabetes & $54(12.4)$ & $60(10.8)$ & 0.414 & $26(8.8)$ & $26(12.4)$ & $8(15.7)$ & 0.208 \\
\hline Hypertension & 134(30.9) & $158(28.4)$ & 0.390 & $73(24.6)$ & $68(32.5)$ & $17(33.3)$ & 0.105 \\
\hline Low-HDL & $198(45.6)$ & $264(47.4)$ & 0.578 & $137(46.1)$ & $104(49.8)$ & $23(45.1)$ & 0.681 \\
\hline High- LDL & $204(47.0)$ & $267(47.9)$ & 0.771 & $132(44.4)$ & $113(54.1)$ & $22(43.1)$ & 0.079 \\
\hline High Cholesterol & $252(58.1)$ & $332(59.6)$ & 0.625 & $165(55.6)$ & $137(65.6)$ & $30(58.8)$ & 0.078 \\
\hline High Triglyceride & $251(57.8)$ & $357(64.1)$ & 0.045 & 194(65.3) & $127(60.8)$ & $36(70.6)$ & 0.344 \\
\hline
\end{tabular}

Data are presented as Mean \pm SD or No. (\%). 
Table 2. The hazard ratio of CVD based on family history

\begin{tabular}{|c|c|c|c|c|c|}
\hline Models & Family History & HR (95\%Cl) & $\mathbf{P}$ & HR $(95 \% \mathrm{Cl})$ & $\mathbf{P}$ \\
\hline \multirow{4}{*}{ Crude } & None & & & 1 & \\
\hline & Paternal & $0.47(0.25-0.89)$ & 0.021 & $0.96(0.64-1.45)$ & 0.843 \\
\hline & Maternal & $0.72(0.38-1.36)$ & 0.318 & $1.46(0.97-2.21)$ & 0.068 \\
\hline & Both & 1 & - & $1.98(1.09-3.61)$ & 0.025 \\
\hline \multirow{4}{*}{ Model 1} & None & & & 1 & \\
\hline & Paternal & $0.46(0.24-0.87)$ & 0.017 & $0.96(0.63-1.44)$ & 0.838 \\
\hline & Maternal & $0.72(0.38-1.36)$ & 0.311 & $1.47(0.97-2.22)$ & 0.068 \\
\hline & Both & 1 & - & $1.99(1.09-3.62)$ & 0.025 \\
\hline \multirow{4}{*}{ Model 2} & None & & & 1 & \\
\hline & Paternal & $0.48(0.25-0.91)$ & 0.024 & $1.11(0.73-1.68)$ & 0.624 \\
\hline & Maternal & $0.70(0.37-1.32)$ & 0.268 & $1.56(1.03-2.35)$ & 0.036 \\
\hline & Both & 1 & - & $1.20(1.21-4.01)$ & 0.010 \\
\hline \multirow{4}{*}{ Model 3} & None & & & 1 & \\
\hline & Paternal & $0.48(0.25-0.92)$ & 0.026 & $1.05(0.69-1.59)$ & 0.817 \\
\hline & Maternal & $0.69(0.36-1.30)$ & 0.251 & $1.41(0.93-2.15)$ & 0.104 \\
\hline & Both & 1 & - & $2.05(1.12-3.74)$ & 0.019 \\
\hline
\end{tabular}

Paternal and maternal history were compared to both parental history (left column) and none-familial history (right column); Data adjusted in Model 1 with: Gender, Model 2: Age and Gender and Model 3: Age, Gender and BMI.

analysis, maternal history of CVD $(\mathrm{P}=0.047)$, history of CVD in both parents $(\mathrm{P}=0.032)$, maternal history of $\operatorname{HTN}(\mathrm{P}=0.005)$, as well as history of DM $(\mathrm{P}<0.001)$ and smoking $(\mathrm{P}=0.026)$ were determined as risk factors for the occurrence of CVD in offspring.

Female gender $(\mathrm{P}=0.005)$, age of more than 60 years $(\mathrm{P}<0.001)$ and obesity $(\mathrm{BMI}>30)(\mathrm{P}=0.028)$ makes offspring more susceptible to CVD. Furthermore, high total cholesterol levels $(>200 \mathrm{mg} / \mathrm{dL})(\mathrm{P}=0.62)$, high serum level of LDL $(>150 \mathrm{mg} / \mathrm{dL})(\mathrm{P}=0.77)$ and low HDL $(<30 \mathrm{mg} / \mathrm{dL})(\mathrm{P}=0.57)$ did not affect the risk for CVD in offspring. While a high triglyceride level (>200 mg/ $\mathrm{dL})(\mathrm{P}=0.045)$ relatively impacts the risk for CVD in offspring (Table 1).

Only maternal history of HTN has a significant effect on the incidence of CVD. Nevertheless, adjusted analysis for gender, age and BMI clarified that the age of CVD incidence in patients with positive family history is low- er than the normal population (57.9 \pm 10.9 vs. $61.9 \pm 11.1$ years, $\mathrm{P}=0.031$ ) (Table 2). However, there were no significant differences between paternal and maternal family history in the onset age of CVD in the offspring $(\mathrm{P}=0.835)$. Moreover, the mean age of CVD incidence in offspring with paternal, maternal and both history of HTN is significantly lower than the group without parental history of HTN $(\mathrm{P}=0.013)$.

\section{Discussion}

The obtained results indicated that women with a maternal history of CVD are more susceptible to CVD. Thus maternal side history seems to be a risk factor which needs regular screening for CVD. In addition to a positive parental history, some risk factors in offspring such as DM, age of more than 60 years, female gender and obesity (BMI>30) are associated with higher risk of CVD. Such characteristics could be explained by the impact of conventional risk factors for CVD in the general popula- 
tion. These factors in addition to maternal history of HTN and just history of both parents are associated with slightly greater CVD risk in male offspring. The accumulation of these risk factors together in the family may lead to the occurrence of CVD in the earlier ages of offspring.

Several studies have addressed the association between family history and CVD (Barrett-Connor \& Khaw, 1984; Hunt, Gwinn, \& Adams, 2003; Woodward, Brindle, \& Tunstall-Pedoe, 2007). Prospective, community-based studies, and two-generation Framingham study cohort reported that the impact of parental stroke was greatest on early stroke incidence, before the age of 65 years. Genetic epidemiology of stroke is relatively unexplored and gender-specific aspects of this relationship are poorly explained (McBride, Hale, Subramanian, Badger, \& Bernstein, 2014). The results of this investigation demonstrated marked gender-specific differences of the relationship between paternal and or maternal history of CVD and the occurrence of CVD in offspring.

Our data indicated that maternal transmission of CVD imposes a greater risk on offspring, especially in females. Despite the lack of consensus on the impact of family history on CVD in offspring, our results is consistent with previous studies (Hunt et al., 2003; Qureshi et al., 2012). The incidence of CVD in women is more affected than men by parental history of the disease. Therefore, parental history is a better predictor for female offspring. This finding is consistent with a previous study that indicated a gender-specific relationship between maternal history of CVD, left ventricular hypertrophy and HTN in female patients with CVD events (Tentschert et al., 2003).

Extensive assessment of family history in development of CVD among offspring's maternal or paternal grandfathers, grandmothers and other relatives may be helpful for better stratification of risk factors in offspring. The risk for CVD in female offspring with positive family history of CVD is higher. But it should be kept in mind that this higher conferred risk could not be introduced to the person as a cause of life-long stress. These data should be applied correctly for screening at risk population for primary prevention. In order to accurately assess inheritance traits in children, the environmental factors and lifestyle in the family should also be taken into account.

Family history impacts the chance of catching CVD in the offspring. It is necessary to conduct initial and regular screening of CVD, in female offspring with maternal history of CVD. This susceptible population should be targeted for screening and preventive measures.

\section{Ethical Considerations}

\section{Compliance with ethical guidelines}

All methods of this study were approved by Local Ethic Committee (Code: 82112).

\section{Funding}

This research did not receive any specific grant from funding agencies in the public, commercial, or not-forprofit sectors.

\section{Authors contributions}

The Authors contributions is as follows: Design of the study, obtaining funding: Alireza Khosravi; Drafting, revising and final approval of the manuscript, supervision: Mohaddeseh Behjati; Data acquisition and statistical analysis: Minoo Dianatkhah and Fatemeh Noori; Data acquisition and revising: Majid Nejati; and Design of the study and technical support: Nizal Sarrafzadegan.

\section{Conflict of interest}

The authors certify that they have no affiliation with or involvement in any organization or entity with any financial interest, or non-financial interest in the subject matter or materials discussed in this manuscript.

\section{Acknowledgments}

The authors thank the chairman and staff of the Isfahan Cardiovascular Research Center.

\section{References}

Aparicio, H. J. \& Seshadri, S. (2017). Familial occurrence and heritability of stroke. In: P. Sharma, \& J. F. Meschia (Eds.), Stroke Genetics (pp. 9-20). Berlin: Springer. [DOI:10.1007/978-3-319-56210-0_2]

Bak, S., Gaist, D., Sindrup, S. H., Skytthe, A. \& Christensen, K. (2002). Genetic liability in stroke a long-term follow-up study of Danish twins. Stroke, 33(3), 769-74. [DOI:10.1161/ hs0302.103619] [PMID]

Barrett-Connor, E. \& Khaw, K. (1984). Family history of heart attack as an independent predictor of death due to cardiovascular disease. Circulation 69(6), 1065-9. [DOI:10.1161/01. CIR.69.6.1065] [PMID]

Chung, J. W., Kim, B. J., Han, M. K., Kang, K., Park, J. M., Park S. S., et al. (2016). Family history and risk of recurrent stroke. Stroke, 47(8), 1990-6. [DOI:10.1161/STROKEAHA.116.013148] [PMID] 
Floßmann, E., Schulz, U. G. \& Rothwell, P. M. (2004). Systematic review of methods and results of studies of the genetic epidemiology of ischemic stroke. Stroke, 35(1), 212-27. [DOI:10.1161/01.STR.0000107187.84390.AA] [PMID]

Huang, Z., Huang, P. L., Panahian, N., Dalkara, T., Fishman, M. C. \& Moskowitz, M. A. (1994). Effects of cerebral ischemia in mice deficient in neuronal nitric oxide synthase. Science, 265(5180), 1883-5. [DOI:10.1126/science.7522345] [PMID]

Hunt, S. C., Gwinn, M. \& Adams T. D. (2003). Family history assessment: Strategies for prevention of cardiovascular disease. American Journal of Preventive Medicine, 24(2), 136-42. [DOI:10.1016/S0749-3797(02)00586-X]

Jood, K., Ladenvall, C., Rosengren, A., Blomstrand, C. \& Jern, C. (2005). Family history in ischemic stroke before 70 years of age. Stroke, 36(7), 1383-7. [DOI:10.1161/01. STR.0000169944.46025.09] [PMID]

Jousilahti, P., Puska, P., Vartiainen, E., Pekkanen, J., \& Tuomilehto, J. (1996). Parental history of premature coronary heart disease: An independent risk factor of myocardial infarction. Journal of Clinical Epidemiology, 49(5), 497-503. [DOI:10.1016/0895-4356(95)00581-1]

Kim, H., Friedlander, Y., Longstreth, W., Edwards, K. L., Schwartz, S. M. \& Siscovick D. S. (2004). Family history as a risk factor for stroke in young women. American Journal of Preventive Medicine 27(5), 391-6. [DOI:10.1016/j.amee pre.2004.08.008] [PMID]

McBride, C. A., Hale, S. A., Subramanian, M., Badger, G. J. \& Bernstein, I. M. (2014). The relationship of a family history for hypertension, myocardial infarction, or stroke with cardiovascular physiology in young women. Reproductive Sciences, 21(4), 509-16. [DOI:10.1177/1933719113503402] [PMID] [PMCID]

Øygarden, H., Fromm, A., Sand, K. M., Eide, G. E., Thomassen, L., Naess, H., et al. (2015). Stroke patients' knowledge about cardiovascular family history-the Norwegian Stroke in the Young Study (NOR-SYS). BMC Neurology, 15, 30 [DOI:10.1186/s12883-015-0276-6] [PMID] [PMCID]

Qureshi, N., Armstrong, S., Dhiman, P., Saukko, P., Middlemass, J., Evans, P. H. et al. (2012). Effect of adding systematic family history enquiry to cardiovascular disease risk assessment in primary care: A matched-pair, cluster randomized trial Annals of Internal Medicine, 156(4), 253-62. [DOI:10.7326/00034819-156-4-201202210-00002] [PMID]

Sarrafzadegan, N., Sadeghi, M., Oveisgharan, S. \& Iranipour, R. (2013). Incidence of cardiovascular diseases in an Iranian population: The Isfahan cohort study. Archives of Iranian Medicine, 16(3), 138-44. [PMID]

Sarrafzadegan, N., Talaei, M., Sadeghi, M., Kelishadi, R., Oveisgharan, S., Mohammadifard, N., et al. (2011). The Isfahan cohort study: Rationale, methods and main findings. Journal of Human Hypertension, 25, 545-53. [DOI:10.1038/jhh.2010.99] [PMID]

Seshadri, S., Beiser, A., Kelly-Hayes, M., Kase, C. S., Au, R., Kannel, W. B., et al. (2006). The lifetime risk of stroke estimates from the Framingham study. Stroke, 37(2), 345-50. [DOI:10.1161/01.STR.0000199613.38911.b2] [PMID]

Seshadri, S., Beiser, A., Pikula, A., Himali, J. J., Kelly-Hayes, M., Debette, S., et al. (2010). Parental occurrence of stroke and risk of stroke in their children the Framingham study. Circulation, 121(11), 1304-12. [DOI:10.1161/CIRCULATIONAA HA.109.854240] [PMID] [PMCID]
Sholtzr, I., Rosenmanr, H. \& Brandr, J. (1975). The relationship of reported parental history to the incidence of coronary heart disease in the western collaborative group study. American Journal of Epidemiology, 102(4), 350-6. [DOI:10.1093/oxforde journals.aje.a112171]

Tentschert, S., Greisenegger, S., Wimmer, R., Lang, W. \& Lalouschek, W. (2003). Association of parental history of stroke with clinical parameters in patients with ischemic stroke or transient ischemic attack. Stroke, 34(9), 2114-9. [DOI:10.1161/01.STR.0000087361.60511.E7] [PMID]

Tian, T., Jin, G., Yu, C., Lv, J., Guo, Y., Bian, Z., et al. (2017). Family history and stroke risk in China: Evidence from a large cohort study. Journal of Stroke, 19(2), 188-95. [DOI:10.5853/ jos.2016.01270] [PMID] [PMCID]

Woodward, M., Brindle, P. \& Tunstall-Pedoe, H. (2007) Adding social deprivation and family history to cardiovascular risk assessment: The ASSIGN score from the Scottish Heart Health Extended Cohort (SHHEC). Heart, 93(2), 172-6. [DOI:10.1136/ hrt.2006.108167] [PMID] [PMCID] 